\title{
Treatment, Overdose, and Finding the Road to Recovery
}

MICHAEL T. FLAHERTY

Private Clinical Practice

Previously with St. Francis Institute for Psychiatry and Addiction Services and the Institute for Research, Education and Treatment of Addiction

Knowing is not enough; we must apply. Willing is not enough; we must do.

-Goethe

To address the role of treatment in Pennsylvania's overdose challenge, certain ideological impediments must be identified and addressed. A separateness of harm reduction from treatment as different approaches, a separateness of public health and public safety as partners in the solution, of public health from private insurance for treating the illness must all be overcome by a prioritized, unified vision. Without this, today's policies cannot build on the available twentyfirst-century science in both specialty care and general practice-let alone in our communities. Coupled with societal factors including universal stigma for the illness and those suffering it, these divides have created fertile ground for today's predictable epidemic. Through collective determination with increased access to described interventions and treatment, including expanded access to medication-assisted treatments and an enhanced, broadened, skilled interdisciplinary and peer workforce built on a "recovery" philosophy, locally implemented efforts with county, state, and federal leadership can reverse the epidemic.

\section{The Birth and Growth of a Predictable Epidemic}

hat happens when the largest preventable illness in America is historically minimized, undertreated, or simply denied (Robert Wood Johnson Foundation 2001; U.S. Department of Justice

COMMONWEALTH, Volume 20, Issue 1 (2018). (C) 2018 The Pennsylvania Political Science Association. ISSN 2469-7672 (online). http://dx.doi.org/10.15367/com.v20i2-3.188. All rights reserved. 
2001)? Prevention is minimized, and even though effective drug treatment exists, most people who need treatment don't receive it.

There are many reasons for this, including: costs of treatment; demands of other more "acceptable" illnesses; inadequate accessibility or availability of treatment; or the belief of patients that they can handle the problem without treatment, i.e., not being ready to stop using-a symptom of the illness. There is also a lack of health insurance coverage; privacy concerns; and, most recently, the sheer power of the illness that took over 63,000 American lives in 2016-4,642 in Pennsylvania alone (Lord 2018; U.S. Drug Enforcement Agency and University of Pittsburgh School of Pharmacy 2017) -all complicated by an even greater barrier: stigma.

Adding to these historical challenges is the shortage of a sufficiently skilled, prepared, and receptive health care workforce. Many who are positioned to address addiction lack adequate training or the knowledge to effectively assess, refer, intervene, or treat patients once they are identified as in need of treatment. Even if identified, a treatment capacity exists for only $10.8 \%$ who might need it (Hoge et al. 2013; Hyde 2013).

Opioid dependence and treatment especially remain fraught with challenges: stigma; skepticism regarding the effectiveness of treatment alternatives; well-intended but often conflicting or underresourced plans of leaders and provider agencies dependent on site-based service; restrictive funding and payment methodologies focused on enrolled clients within their agency; and treatment that is not necessarily grounded in the science of recovery (ONDCP 2013). As this already-devastating epidemic continues to build destructive momentum, there is a fundamental question facing our country, our Commonwealth, and our communities: Is this an epidemic that we will mobilize to halt or to at least significantly slow, or is it one that we will minimally address and build industries around?

To mobilize effectively, existing ideological dichotomies must be acknowledged and addressed. Treatment itself is often held distinct from other solutions such as harm reduction or medication management that should, instead, be viewed as early-stage platforms for treatment and recovery (White and Mojer-Torres 2010). Public and private practice and funding remain largely distinct, generating separate systems of public and private care. Most notably, when adding the importance of overdose prevention to treatment, "public safety" must be joined and coordinated with public health efforts, just as "prevention" and "harm reduction" must join with treatment in a broader effort to attain and sustain community, family and individual support, health, wellness, and recovery (Hickton and Leary 2015). Given these historical obstacles and others, e.g., treating pain as the fifth vital sign (Campbell 1996; Kolodny 
et al. 2015), as well as the extraordinary profits that continue to be reaped by some from this illness, this "epidemic" has long been coming and should be no surprise.

\section{Why Treatment Has Fallen Short}

\section{Stigma and Denial}

No barrier to treatment is a more formidable obstacle than stigma, in the many forms that it takes. Most fundamentally, even the acceptance of the illness as an illness or disease remains denied by many in society and leadership, creating a deep public bias that is hard to see, let alone overcome. Despite an extensive science that documents the illness medically, intergenerationally, and chronically, with lethal outcomes if not addressed, many, including many public leaders, continue to hold the illness as self-caused, a bad choice gone worse, or a moral weakness for which society should give only limited resources, help, tolerance, and compassion.

Overlooked is the fact that at some point for each person suffering addiction, without clinical intervention, choice is compromised, if not lost, and society's denial of this now costs the United States over $\$ 700$ billion dollars annually (NIDA 2018c). Consider the cost figures (see Tables 1 and 2) for 2014 and 2016, the last year for which comparative cost data are available, remembering that the drug abuse epidemic has grown exponentially since then.

\begin{tabular}{|l|}
\hline $\begin{array}{l}\text { Table } 1.2014 \text { and } 2016 \text { Costs of Drug Abuse Compared to Other Chronic } \\
\text { Conditions }\end{array}$ \\
\hline Substance Use in 2016 cost society $\$ 700$ billion annually \\
\hline Substance Use in 2014 cost society $\$ 484$ billion annually \\
\hline Diabetes in 2014 cost society $\$ 131.7$ billion annually \\
\hline Cancer in 2014 cost society $\$ 171.6$ billion annually \\
\hline Sources: CDC 2014 . \\
\hline
\end{tabular}

\section{Table 2. Pennsylvania Overdose Data 2014 and 2016}

2016 Overdose deaths per 100,000 people: 37.9 (5th highest in nation) National average 14.7

2014 Overdose deaths per 100,000 people: 12.7 (10th highest in nation)

Pennsylvania Opioid Painkiller Prescriptions active per 100 citizens, 82 to 95

(21st largest in country)

Sources: PPG 2017; Sauter 2016; CDC 2014. 


\section{Stigma and the Lack of Unified Vision}

Today's health policy lacks both a unifying vision and, therefore, a unified will to prioritize and mobilize to prevent and treat addiction and build a capacity for community and individual recovery. In fact, the barrier of stigma is reinforced by basic features of the existing system, within both the health care community and the general population. Consider, for example, that addiction often is treated as criminal, while pain management is treated as medical. Pain management treatment tends to be delivered in medical settings, while addiction, if addressed at all, is more often addressed in public clinics or in jails, or in the case of overdose, by hospital emergency rooms or publicly employed first responders, often in public places such as bathrooms, cars, or churches.

Stigma is the overarching barrier if we are to solve substance use, addiction, overdose, and the challenge of pain management. Today's health policies and services are built upon accepted societal and medical stigma, against both the illness and the person suffering from it. This is so pervasive that many who struggle with addiction deny it, hide it, and do not seek help for it. Hospital ERs daily turn away those who have a higher probability for mortality than others admitted for suicidal ideation or other life-threatening medical conditions (medical stigma), even as those same facilities shun adding treatment capacity, and more costly jail populations and the number of overdoses grow.

Fewer than $11 \%$ of U.S. medical schools teach courses in addiction (Morely-Forster et al. 2013), and half of today's graduating physicians report "feeling unprepared" to treat it (Mezei and Murison 2011). As a result, alternative systems of care and community supports such as nonhospital withdrawal management and rehabilitation, recovery centers, halfway houses, and family and peer supports have emerged to address this major illness outside of mainstream medicine. Without the needed medical leadership to restructure a stigma-based system of care, the unifying vision of what is needed to prevent and address overdose or addiction and facilitate both community and individual recovery cannot take shape. Today, substance use pleads for attention from medicine.

For example, the medical and general population's understanding of addiction and pain treatment remain separate and divided, e.g., addiction is often seen judgmentally as a weakness, while pain is viewed as a medical condition - at least until it leads to addiction. Stigma becomes further translated to clinical treatment when driven more by assured payment and level of service entered than by assessing the nature of the illness presented, matching that assessment to a level of care (Mee-Lee et al. 2013), and meeting the 
needs of the person continually along its progressive and at times regressive trajectory by offering each person an opportunity for recovery at each level and encounter.

There are other compelling examples of science unaddressed. For example, according to the National Institute on Drug Abuse Principles of Quality Care, any treatment episode for a substance use disorder that is less than 90 days in duration is clinically of little value (NIDA 2018b). How does Pennsylvania stack up against this recommendation? How many in treatment today receive at least a 90-day episode of care? Shouldn't this be a policy? It isn't.

Or, at the service level, how many providers still claim that the very medications proven effective to treat addiction are a cop-out, and are simply replacements for illicit drugs? How many treatment systems involuntarily discharge a person from treatment for exhibiting the symptoms of the very illness for which they sought help, e.g., positive urine screens in treatment? And what makes us believe that those who suffer addiction can just stop? If a person cannot access care and continually fails despite losing his or her job, family, health, or freedom by ending up in jail, does it not speak of the absence of self-control? When a person is revived from his or her fourth overdose and expresses anger at the first responder/Samaritan for taking life-saving action, does it not speak of an absence of mental competence? This is the power of addiction that must be understood and addressed for solutions to be effective.

Systemic stigma can also be clearly seen in the very language used to describe those suffering from this illness or disease: e.g., "addict," "junkie," "dope head," "substance abuser." These are all terms that cement a context of fault and add to the resistance, rejection, or failure of treatment. These are "persons suffering with addiction" or "persons in recovery." Language matters, and an "Addictionary" designed for the illness exists (Kelly, Dow, and Westerhoff 2010).

Establishing a vision to address overdose and substance use in Pennsylvania and each region, county, or community can be a first step to crafting an effective solution. Policies and systems of care should be steered to fulfill this vision. The author has suggested as one vision, "providing each person and community the most efficient and effective care along a continuum of assessed severity and need capable of addressing the illness and initiating recovery."

From within the framework of this vision, life-saving treatments, including medical stabilization and medication support, could be initiated before more expensive approaches involving hospitalization and rehabilitation are employed, without compromising the goal of attaining individual recovery (White and Mojer-Torres 2010). Incarceration, when necessary, should offer 
medical stabilization, the initiation of treatment and recovery, and, upon completion, preparation for safe community reentry from incarceration, including medication and linkage to peer supports. Medication-assisted treatment in correctional settings has been shown to reduce the risk of overdose upon release (Wakeman and Rich 2015). Because the deployment of these practices is too infrequent, overdoses remain highest in those who have dropped out or been discharged from treatment or who are returning from rehab or jail, because their lower physical tolerances are too easily overcome by the powerful drugs that await them in the community.

Treatment must be continuous and aligned to the principles of chronic disease management, with coverage and access assured even between systems (e.g., jail and community) or treatment agencies (e.g., outpatient treatment and inpatient care). Insufficient treatment capacity, coupled with stronger illegal drugs and the widespread trafficking in those drugs driven by greed, has fueled this predictable epidemic. As to payment, a private fee-for-service model, without any record of success in public health, has been foisted upon a national public health problem with constraints that make it difficult to reach those most at risk for overdose or their families. These payment mechanisms shape what is offered as treatment. Other reimbursement schemes need to be developed such as funded prevention, brief screening and limited agency funding, case rate funding, and funding for outreach (e.g., peer supports), emergency care coverage, and targeted value-based funding for high-risk persons so that we can reach those most in need to prevent overdose death.

To overcome inherent medical stigma, we must first see it. We must acknowledge that substance use treatment, except for pain management, has become segregated from general medical care and generalist and specialist training and practice (vs. Common Elements of Success: "Integrated Care" below). As a result, rather than coalescing a prioritized will to address an epidemic, profitable industries have arisen to address parts of it. Jails, courts, and child protective services are functioning at, or in some cases beyond, maximum capacity. Police have become first responders, new profitable and more addictive medications have been developed, acute treatment systems build on treating other advanced but related medical disorders, emergency rooms see overdoses daily, etc. The needed specialty demands for community prevention, intervention, treatment, and recovery remains resourced to below $3 \%$ of the now nearly $\$ 700+$ billion annual cost of the illness (NIDA 2016e, 2018c).

Substance use effects all populations. The opioid epidemic has brought an added 1.35 million Americans into poverty and lowered the national life expectancy (now 78.6) in the United States each year for the past six years (NIDA 2016c; Pittsburgh Post-Gazette Editorial Board 2017; U.S. Department 
of Health and Human Services, Office of the Surgeon General 2016). Unique stigma exists also toward the poor, female, adolescent, older, or racial minorities, etc. Each has its own face that must be transcended with specificity and a sensitive transformation of science to reach its mark.

Even treatment itself stigmatizes the person by focusing almost exclusively on the pathology, measuring success as the attainment of abstinence, compliance, and adherence to treatment, too often leaving out the emerging science and positive added outcomes of recovery and the many measures of it (Flaherty, Kurtz, and White 2014; White and Kurtz 2008). With a vision and an awareness of the pervasiveness of stigma we can begin to construct a healthier, more relevant approach to a prevention and treatment system that can bring solutions, hope, and science to this epidemic.

\section{Treatment Capacity and Workforce Development}

Another barrier to reducing overdoses is the existing capacity for substance use treatment. Today, the United States has a national capacity for only $10.8 \%$ of those who would meet clinical criteria for such treatment (ONDCP 2013). In Pennsylvania most programs for those severely addicted operate at capacity and with waiting lists.

Moreover, the science itself has changed from seeing the illness as an acute or temporary problem (e.g., like a broken bone or a cold) to being potentially lifelong and best addressed within a "continuum of care" as a chronic illness (Appendix A). This approach would be like that taken with other chronic conditions such as diabetes, HIV, high blood pressure, depression, etc., and has been described in paradigm-changing research since the turn of the century (McLellan et al. 2000; Scott and Dennis 2007; Flaherty 2006). Health care for chronic conditions is very different from the care for acute, episodic illnesses, and our state agencies and treatment providers, already too few, struggle in an earn-to-survive, fee-for-service model often offering only what the specific location and level of care provides.

Substance use calls for experiential (i.e., in real world) support while having vigorous referral to the levels of medical care necessary to best address everyone (Commonwealth of Pennsylvania Department of Drug and Alcohol Programs 2014; Mee-Lee et al. 2013). But the severity of the illness and its science have moved faster than the services and skills of the workforce to address it in a community. New technologies, medications, professional collaborations, complex multiple diagnoses, increased collaboration with peer and family supports, care management, electronic health records, parity, and health insurance or managed care have all led to increased expectations for 
modernization without increased dollars to meet the added burden to frontline providers.

In short, today's system, while deserving our full respect for what it does accomplish, is drastically overburdened by existing calls for service, modernization, technology, change, and accountability. As a result, today's substance use specialty workforce suffers a $30 \%-40 \%$ annual attrition of workers (SAMHSA 2013). Additionally, the illness appears in all general medical conditions and settings, creating a need for exponential cross-disciplinary integrated care and clinical expansion, training, and development (SAMHSA 2013).

We need to strengthen our application of prevention science (Kolodny et al. 2015; Tarter, Cochran, and Reynolds 2018), expand opportunities for earlier intervention in general medical care, and increase treatment capacity, especially with medication support-linking each person and his or her family to recovery science and peer and family supports. Substance use treatment needs to be a focus across all medical disciplines to become a more modernized interdisciplinary workforce with screens and assessments, integrated treatment, and ongoing recovery checkups in all general and specialty medical settings, e.g., primary care, health centers, general health care, and across all hospital disciplines. This broader, more educated, and more competent collaborative health care workforce with peer and community involvement is the only workforce capable of reaching addiction and ultimately reducing overdose (Hoge et al. 2013, 2017).

\section{Addiction, Overdose, and the Brain-The Power of Addiction}

Addiction has a complex biological nature. This illness has the power to impact a person's brain and create an insatiable immediacy for the need for drugs that removes judgment from the person, at least temporarily, obviating the choice to not seek more drugs or to never use again. Neurologists now believe this may possibly be tied to repetitive but rebuffed electrical impulses (cravings) in the brain. Short of overdose and death, this loss of choice is the first, worst, and most underestimated manifestation of the illness. It can be said that the person at this point does not really have an addiction; instead, the addiction has him or her. Moreover, studies have shown there is a genetic transfer of vulnerability for the illness to offspring, creating a predisposition for increased risk in the future (NIDA 2016a; Sliboda, Glantz, and Tarter 2012).

Addiction, at whatever level of severity (Mee-Lee et al. 2013), too often leads to a life of misery and death, with generational and broader societal impacts and decades of cost. For these reasons, the American Society on Addiction Medicine and the National Institute of Drug Abuse classify addiction as a 
"disease" (ASAM 2017; NIDA 2018a). This is a classification that society, policymakers, public health professionals, law enforcement, and others must understand and embrace if we are to properly assess the disease and appreciate its power, lethality, and costs. Only by doing so can we adequately design the steps to effectively address addiction while building individual, family, and community recovery based on medical safety and continued wellness.

The power of addiction can remove choice cognitively and experientially. Once a person is stabilized medically, treatment must not just address pathology but also access and build recovery strengths in individuals, families, and the community, i.e., build measurable recovery capital, resiliency, and strength (Granfield and Cloud 1999). Treatment must be medically precise, person-centered, and ongoing, while continually offering hope and recovery. A consensus definition of recovery, as a unifying construct for all, was achieved in 2012 by SAMHSA:

Recovery is a process of change through which individuals improve their health and wellness, live a self-directed life, and strive to reach their full potential. SAMHSA has delineated four major dimensions that support a life in recovery: health, home, purpose and community.

The vision of recovery is grounded in medical stability and returned cognitive capacity. Both take time.

When Treatment Becomes the Problem-Pain, Prescriptions, and Diversion

Reportedly, as many as $80 \%$ of those who are currently addicted to opioids began their addiction with prescription pain medications (NIDA 2018a; Muhuri, Groener, and Davies 2013; Jones 2013). In 1995, the president of the American Pain Society introduced a campaign entitled, "Pain is the Fifth Vital Sign," which encouraged health care professionals to assess pain with the same "zeal" as they did other vital signs. This campaign suggested increased access to opioids for chronic, noncancer pain (Campbell 1996), and was followed by thousands of pain-related educational presentations, sponsorships, and grants funded by big pharma across the country (U.S. GAO 2003).

During this campaign, some researchers inaccurately proclaimed the risk of addiction and tolerance with real pain to be low, adding that concerns about addiction should not constrain prescribing (Porter and Jick 1980; Fishbain et al. 2008). Prescriptions of opioids soared, as has addiction (U.S. GAO 2003). Today, Pennsylvania has active opioid prescriptions sufficient for up to $90 \%$ 
of its citizens to have their own full prescription. Pharma is big business in Pennsylvania and across the nation (CDC 2017a), and pain relief is a big part of big pharma. Seeking quick solutions for pain and addiction, and capturing the enormous profits that can be generated, is big business.

While these medications can be a godsend for some, for others they can advance and compound the illness, causing iatrogenic dependence or avoidance of treatment itself by increasing self-dosing. Studies show that conservatively $26 \%$ of those being treated for pain develop dependence (Banta-Green et al. 2009). If not closely medically managed with sustained person-centered care, principles of recovery, and concern for community and population health, diversion becomes a real possibility and problem. With over 255 million opioid pain prescriptions active in 2016, it is estimated that some 11 million Americans used these prescriptions illicitly (Volkow 2017).

Personal medical care is required in all addictions, whether they originated via illicit drugs, addiction treatment, or iatrogenic pain management. The medications used as a part of the treatment for opioid dependence must be promptly available but carefully managed to allow for patient relief while minimizing the possibility of diversion of these medications for illicit use, profit, and harm to the community. Achieving better medical management of such medications is necessary, as is maintaining a continuity for treatment should iatrogenic dependence occur (U.S. Department of Health and Human Services (HHS) 2013). Pennsylvania's model for methadone treatment, which includes close medical management, might provide a successful, proven model for all agonist ${ }^{1}$ treatment for addiction.

New pain management protocols and guidelines (AAPM 2015) have now been developed, suggesting "sliding scale" protocols for pain treatment, often beginning with nonopioid medications. This said, prescribing practices, diversion, and narrow pain management treatment are large sources of today's epidemic and barriers to reducing overdose. On January 1, 2017, Pennsylvania launched its own prescription drug monitoring program (PDMP), which will allow physicians to more accurately know if patients are "doctor shopping," or using opioids or other medications that could be problematic to treatment. A strong clinical use of computerized monitoring has been shown to reduce overdose nationally (CDC 2017b). Pennsylvania is attributing a $12 \%-18 \%$ reduction in opioid prescriptions in its first year to this program (Lord 2018). (For more information on PDMPs in PA, see Mirigian et al. in this issue.)

\section{The Economy and the Cartels}

In the "perfect storm" from which this epidemic has emerged, several lethal and converging forces have been identified to have fueled the epidemic and 
undermined efforts to end it: absence of a unifying vision, denial and unaddressed stigma, inadequate medical preparation, anemic prevention, overburdened treatment, a weary and nonintegrative workforce, excessive and uninformed prescribing in the quest to eliminate pain, and opportunities to profit from the illness itself. A final force is the economy and the drug cartels.

Nationally prominent author and journalist Sam Quinones has laid out what our federal Drug Enforcement Agency also has reported: Pennsylvania, and Appalachia more generally, are major targets for the distribution of cheaper and enhanced heroin from outside our borders that can become lower-cost replacements for prescribed opioids (Quinones 2015). Shunning mafia- and gang-controlled cities, Mexican cartels from small towns (e.g., Xalisco, Mexico) have targeted more rural American communities (e.g., central Ohio, southwestern Pennsylvania, and West Virginia) where their heroin can capture already-existing markets spawned by the heavily prescribed use and misuse of prescribed opioid medications. In a sense, the cartels let strong medical centers and physicians set the stage for their market.

It is no accident that, as prescription practices become monitored and are more constrained, illicit heroin has become more accessible and has been made more powerful with fentanyl (often from China) and the even more deadly carfentanyl. In this progression, without extraordinary intervention, overdoses will increase. Those distributing these less costly, highly lethal substances prey on poverty and victimize captive users as part of their "business as usual" underworld economy. This explains why there is a need for the joint participation of public safety or law enforcement in any overdose reduction plan. Further, with many communities having lost industries and jobs, cultures have arisen in which drug use is common, and in which drug distribution and income, given a seeming lack of alternatives, has become a tolerated part of a struggling existence (Vance 2016). In such communities, drug use goes up, as do specialty medical care needs, where prescriptions can be obtained. Too often these communities and the prescribed medications become the foundation for an economy based largely on selling medications while reverting simultaneously to alternative cheaper, illicit drugs from the cartels. Now we have the perfect storm for the epidemic.

\section{Plans and Resources: Treatment and a Coordinated, Continuing Need for Action}

In addressing opioid use, overdose, and barriers to treatment, science does offer twenty-first-century practices that, when combined with local implementation and enhanced services, are proving effective in reducing overdose while enhancing treatment access and building community resilience and 
recovery. A partial summary of recent national efforts, and Pennsylvania's plan and efforts, can be found in Appendix B.

In scanning these many documents, the reader will quickly see the array and magnitude of both prevention strategies and treatment activities that can be brought to bear to address overdose and reduce death, while simultaneously initiating treatment and recovery. A summary of common strategies proving effective, based on a review of these documents, is below.

\section{Best Practice in Overdose Treatment-Actions}

\section{Prevention as the Best First Practice}

Prevention as a science is covered in another article in this volume (Tarter, Cochran, and Reynolds). Suffice it to say that more than any other proposed or actual solution, preventing the problem in the first place is the optimal solution. Also, by addressing overdose with prevention you can initiate and strengthen treatment. Kolodny and colleagues (2015) have framed just such a model for public health to address the opioid epidemic based on proven prevention science. In their model to address overdose, they align existing SAMHSA prevention science paradigmatic classifications to build the following preventative model.

\section{Primary (Universal) Prevention}

The aim of primary prevention is to reduce the incidence of a disease or condition. Opioid addiction is typically chronic, life-long, difficult to treat, and associated with high rates of morbidity and mortality. Thus, bringing the opioid addiction epidemic under control requires effort to prevent new cases from developing, including greatly reducing access to such medications for pain management, which can lead to iatrogenic dependence.

\section{Secondary (Selective) Prevention}

The aim of secondary prevention is to screen for a health condition after its onset, but before it causes serious complications. Efforts to identify and treat opioid-addicted individuals early during the disease are likely to reduce the risk of overdose, psychosocial deterioration, transition to injection opioid use, and medical complications. One science-based guide of such prevention is NIDA's "Principles of Substance Abuse Prevention for Early Childhood" (2016b).

\section{Tertiary (Indicated) Prevention}

Tertiary prevention strategies involve both therapeutic and rehabilitative measures once a disease is firmly established. The goal of tertiary prevention 
of opioid addiction is to prevent overdose deaths, medical complications, psychosocial deterioration, transition to injection drug use, and injectionrelated infectious diseases. Doing so is accomplished mainly by ensuring that opioid-addicted individuals can access effective and affordable opioid addiction treatment. Here, timely access to treatment, especially those including medication-assisted treatments such as buprenorphine, methadone, and naltrexone (pill or injectable), would fit into a prevention strategy for both the individual and the community. Additionally, certain "harm reduction" strategies would be made more available, e.g., syringe exchange programs and readily available NARCAN accessibility. Such prevention strategy needs to be incorporated into Pennsylvania's Strategic Prevention Framework and Plan and implemented in each county.

By adding what is presented in detail by Tarter, Cochran, and Reynolds in this issue to Kolodny's generally accepted schematic rubric, Pennsylvania could indeed have one of the finest prevention programs in the nation.

\section{Treatment}

\section{Outreach}

An overdose is best addressed by quickly reviving the person from the overdose and connecting him or her immediately to further treatment. This is best achieved by applying naloxone (aka NARCAN) to revive the person if unconscious, and then connecting the survivor, via a "warm handoff," to an agency or professional who can assist the person to obtain treatment without delay. Today in Pennsylvania, the person must agree to such treatment until an involuntary admission or "hard handoff" law is justified and is enacted in Pennsylvania (e.g., upon second overdose or through earlier family intervention).

Overdose drug deaths far exceed death by suicide, e.g., in 2015 the National Institute on Mental Health reported just over 40,000 deaths attributed to suicide (many by drugs) vs. 54,404 overdose drug deaths (Rudd, Seth, and Scholl 2016). Both Pa. 2010 Act 50 Article XXIII-A, section (1) xvii and the Mental Health Procedures Act of 1976 should be reviewed to answer key questions such as: Is the overdosed person evidencing a "clear and present danger to self or others" with a likelihood of possible death within 30 days? Involuntary admission can be to outpatient or inpatient settings. On December 8, 2017, Pennsylvania Senator Jay Costa (D-43) introduced Senate Bill 391 to allow families to obtain court-mandated treatment. While likely to have opposition from civil rights advocates, payers, and even many in recovery, given the power of today's drugs and the severity of the illness with related loss of 
mental competence (hijacked brain) and hope, such examination and revised laws are necessary. Thirty-eight states, including Pennsylvania, currently have some form of involuntary admission law for substance use, but these laws are too cumbersome, unknown, and weak compared to similar laws for mental health. Any new law should include overdose survivors, families of those lost, providers, civil rights and peer advocates, and all counties that will need to educate the public and implement the revised law.

In addressing opioid overdose, individual recovery cannot begin unless the person is alive and physically able to initiate it. Today's typical treatments are too institutionally centric to reach those most at risk. Outreach and novel points of access (e.g., mobile treatment, needle exchanges, food banks, firehouses, hotels, community safe centers, trained pastors, and peer linkage) are potentially productive initiatives, as is involuntary treatment. Pennsylvania has been historically more conservative in its approaches to overdose. It is worth noting, though, that some states and major cities have found successful avenues to treatment through involuntary treatment and by expanding harm reduction approaches such as access to safe-drug consumption/treatment sites, and by changing police responses to low-level crimes such as taking the person to treatment or safe consumption/treatment sites. Seattle's Law Enforcement Assisted Diversion (LEAD) Program is one model highly supported by both the police and the community (Collins, Lonczak, and Clifase 2015). Throughout Ohio and in Pittsburgh, Pennsylvania, police have recently initiated Quick Response Teams as a follow-up to any overdose. ${ }^{2}$

What makes these newer harm-reduction approaches appealing is that they reduce human suffering while lowering overdose and societal costs (e.g., incarceration, health, etc.) and improving access to treatment. Addressing overdose prevention mandates a harm-reduction component within the treatment continuum. Keeping a person alive, while offering an alternative to untreated addiction, is society's mission and task. Beyond that the disease will win.

\section{Medical Stabilization and Treatment}

Medical stabilization from opioid use disorder itself is necessary for a dependent person to return to normal functioning and quality of life and to avoid the many potential consequences of opioid dependence such as trauma, suicide, HIV and hepatitis C infection, family suffering, and early death. Treatment has been proven to address these consequences while improving the overall social functioning of the person and family wellness. The Surgeon General Report (U.S. HHS 2016) and National Institute on Drug Abuse (2018b) outline well the effectiveness of opioid treatment. 
There are a variety of approaches in treating opioid use. The three most common outpatient approaches are treatment in opioid treatment programs (OTPs), generally in methadone clinics, which are monitored and regulated by both the state and federal government (SAMHSA, DEA); office-based opiate treatment programs (OBOTs), generally in buprenorphine dispensing centers, which are unmonitored individual specialty-trained medical practices; and abstinence-based specialty substance use treatment, which can include some medication, e.g., naltrexone (pill or injectable) or psychiatric medication, but usually do not use agonist medication. These comprise most of Pennsylvania's providers and are licensed and monitored by the state. Given the severity of addiction, residential and inpatient care may also be warranted, if available. These, too, may include medication-supported recovery.

OBOTs, the fastest-growing approaches, have strengths and weaknesses, including easier access to medication but lighter medical monitoring, less counseling, and greater opportunity for medication diversion (Alderks 2017). Some more sophisticated OTPs, which have by regulation increased medical oversight and counseling, have begun to incorporate buprenorphine and naltrexone (i.e., Vivitrol) into their treatment protocols, which previously had used only methadone. This progression seems to be moving toward a "comprehensive opioid treatment center" model, which would seem both clinically and scientifically evolutionary and a positive step for all.

Mention must be made of treating opioid- or heroin-dependent pregnant women and their babies. It is estimated that today some 2.1 million Americans use illicit opioids and another 467,000 are addicted to heroin. Studies also indicate that for every five individuals with this illness, there will be one child born with dependence and withdrawal or neonatal abstinence syndrome (Volkow 2014). Across America, births of such babies and the increased burden on the child welfare system are growing at unprecedented rates. The cost and implications of this growth are astronomical if the child is untreated and can be lifelong. However, with early recognition, good prenatal care, and substance use treatment, the outcomes can be brought to near-normal in comparison to nonaddicted populations.

There is a well-developed and exacting science, for both mother and child. ${ }^{3}$ This population should be a priority, and to its credit, Pennsylvania has recently funded a Center of Excellence, the Maternal Addiction Treatment, Education, and Research (MATER), at Thomas Jefferson University in Philadelphia. Thomas Jefferson University has been a national and international leader in working with the population for decades, and the work of its new Center of Excellence needs to be vigorously disseminated. 
Augmenting these "outreach" and "treatment" services are local peer groups and 12-step fellowships, such as Narcotics Anonymous, Alcoholics Anonymous or Al-Anon, and many nonfellowship free supports such as Sage's Army (western Pennsylvania) Family Resource Center (www.familyresourcectr .org), Bridge to Hope (western Pennsylvania), and other organizations generally accessible through local county drug and alcohol programs. All can assist in identifying sources of help and potential avenues to recovery. Some, like Bridge to Hope, offer parent and family support groups to help cope with loss and ongoing grief as well as to enable family members to identify problems and empower them to action. Community reinforcement and family training (CRAFT) is but one proven educational and training program that prepares family members for earlier, scientifically grounded intervention (Foote et al. 2014). These peers, fellowships and supports, and family groups complement formal treatment and are a modern "must," as part of any ultimate safety net for communities. They have an impact that cannot be overestimated as being vital to any ultimate solution.

All treatment approaches are not equal, nor are they interchangeable. The severity of the illness must be accurately assessed and properly matched to the appropriate level of care so that medical safety and stabilization can be achieved first, creating an opportunity for longer-term treatment and recovery. Too often individuals are turned away from treatment, especially in hospital emergency room settings or by waiting lists in outpatient programs. Such actions very often negate the desire for treatment and increase the probability of overdose. A personal review of overdose death records (unpublished) by this author has shown that over $63 \%$ of the nearly 100 who died from opioid/heroin overdose had sought prior treatment or had prior criminal justice involvement before their demise. Why did that treatment or encounter not stick? Was the treatment appropriate to the presenting need of the person? Would a peer support or medication have made a difference?

When treatment is accessed, the person should be carefully screened for the severity of the presenting illness. The American Society on Addictive Medicine Patient Placement Criteria (Mee-Lee et al. 2013) and the Pennsylvania Placement Criteria (Commonwealth of Pennsylvania 2014) are two excellent examples of the guidance now required in Pennsylvania and some other states to properly place a person in a matched level of care. Further assessment of the severity of the illness can be enhanced through the use of any of several more focused addiction severity measurement scales, e.g., Addiction Severity Index (ASI) (McLellan et al. 1980); ${ }^{4}$ or with withdrawal management instruments such as The Clinical Opiate Withdrawal Scale (COWS) (Wesson and Ling, 2003), or the Severity of Opiate Dependence Scale (Sutherland et al. 
1986). Residential or hospital care may first be warranted by the results of this critical initial assessment.

If outpatient treatment is recommended, methadone (OTP) or buprenorphine (OBOT) or naltrexone injection (nonagonist Vivitrol) treatment should be considered as being more successful in preventing overdose and providing more time to stabilize the patient for early recovery. Standard outpatient treatment may not use agonist medication. However, in today's populations of stronger opioids and heroin, both the World Health Organization ${ }^{5}$ and SAMHSA (2016) recommend that all individuals with an opioid dependence diagnosis be considered for medication-supported treatment. Standard outpatient treatment may use naltrexone or the monthly injectable Vivitrol or other nonagonist medications to fortify abstinence. Vivitrol, an opioid blocking agent, is also used in OTPs and OBOTs when it has been determined medically safe to do so. It is also successfully used with those newly returning to the community from jail or rehab.

Sadly, only $20 \%$ of the people addicted to opioids today receive treatment (U.S. HHS, Office of the Surgeon General 2016). This problem is made even more acute by the insufficient preparation of large numbers of practicing U.S. physicians in the treatment of addictions. Only $2.2 \%$ of all physicians are approved to use the most common treatment medication, buprenorphine, and $90 \%$ of those $2.2 \%$ are practicing in urban areas, leaving most rural counties without proper care (NIDA 2016d). Many barriers and challenges exist for communities to recruit and retain physicians (or nurse practitioners) trained in addictions or to attract enough opioid-treatment practitioners (DeFlavio et al. 2015; Huhn and Dunn 2017; Stein et al. 2015). Increasing properly managed access to medication support may be the greatest single treatment step that can be taken today to slow overdose deaths and give treatment and recovery a chance.

Once matched to one of seven possible levels of care (Mee-Lee et al. 2013) for initial treatment, the person should proceed along a continuum or levels of care over time based on assessed progress and medical judgment. Once in treatment, the person usually remains in treatment for a sufficient period to be medically stable and initiate early recovery. As noted above, the National Institute on Drug Abuse suggests a 90-day continuum of care as minimal (NIDA 2018b). Medication-assisted treatment often takes years and may continue for a lifetime. Still, in general, for every dollar spent in substance use treatment minimally a $\$ 7$ savings to society is returned; $\$ 8$ for medication-supported treatment due partly to decreases in criminal behavior and re-incarceration (NIDA 2018c). Put simply, treatment more than pays for itself! 


\section{Common Elements in Successful Treatment and Overdose Prevention}

Having underscored earlier prevention and access to specialized, patient matched, skilled treatment with general medical care as a basic need, the author's personal experience and a review of the clinical guidance listed in Appendix A has allowed him to identify common elements as cross-cutting, impactful, and promising. These common elements for such success are discussed in the next sections.

\section{Ready Access to Treatment and a Continuum of Care}

For a treatment system to be effective, it must provide ready access to treatment and a continuum of care over a sufficient length of time so that the patient achieves personal safety and medical stability and is positioned to have a realistic opportunity for recovery. Twenty-four/seven crisis centers, urgent care centers, mobile units, and emergency rooms, when properly organized and staffed, have proven to be effective as points of first access for medical care and the initiation of medication and treatment (D'Onofrio, O'Connor, and Pantalon 2015).

\section{Medication-Assisted Treatment (MAT)}

Timely access to medication-assisted treatment is also critical to the creation of an effective treatment system. These medications are used to help a patient function without illicit opioids or alcohol while balance is gradually restored to the brain circuits that have been altered by prolonged substance use. It should be noted that patients who receive MAT for fewer than 90 days have not shown improved outcomes; similarly, detox alone is almost universally not successful (U.S. HHS, Office of the Surgeon General 2016, 4-21). Some studies suggest that individuals who receive MAT for fewer than three years are more likely to relapse than those who are in treatment for three or more years (American Medical Association 1998; Joseph, Stancliff, and Langrod 2000; Kakko et al. 2003). Three medications are most commonly used to treat opioid use disorders: methadone, buprenorphine, and naltrexone.

More recently the SAMHSA (2016) and American Medical Association (2018) published guidance that, recognizing the increased addictive power of today's medications and illicit drugs, suggests:

Opioid withdrawal alone is not recommended for treatment of opioid use disorders in most patients because of increased risks of overdose death and infectious disease, particularly HIV through intravenous drug use, following detoxification (moderate quality evidence, strong 
recommendation). In the absence of contraindications, medically supervised opioid agonist treatment should be offered to patients. Buprenorphine/naloxone is the preferred first-line treatment. Methadone is an alternative in certain patient populations (high-quality evidence, strong recommendation). (SAMHSA 2016, 338)

\section{Naloxone/NARCAN}

Community awareness, training, and ready access to naloxone (NARCAN) throughout communities are critical to saving lives, thereby preserving opportunities for treatment. Among those needing access are active users, counselors, families, first responders, schools, ERs, hotels, jails, fire stations, and other locations that may be potential points of connection between survivors and providers of treatment via "warm handoff" or person-to-person connectivity. Anyone with a diagnosis of opioid dependence and his or her family members should have NARCAN. Of course, access to NARCAN will not be enough if those who have it do not know how to use if effectively. What also is needed, therefore, is strong community prevention awareness and training, including special training (e.g., CRAFT, how to use NARCAN) for parents and other family members. Such interventions generally are protected by supportive Good Samaritan laws, which provide an important measure of legal protection for those providing help as volunteers.

\section{Prescription Drug Monitoring Program}

Active participation and coordination of prescribing via a prescription drug monitoring program (PDMP) by all prescribers is another key step. Pennsylvania became the 49th state to adopt such a program through Act 191 of 2014. That program went into effect on January 1,2017, and already seems to have made a difference in prescribing rates. (For more information on PDMPs in Pennsylvania, see Mirigian et al. in this issue.) Opioid prescribing also can be reduced by following CDC guidelines and alternative pain management techniques. ${ }^{6}$

\section{Other Effective and Suggested Strategies}

\section{Expand Capacity}

Open bed capacity must be increased to meet acute needs. A key policy step would be to seek adjustments to federal restrictions (e.g., federal IMD exclusion) to allow expanded Medicaid and Tricare coverage of residential care. Pennsylvania should advocate for this, either as a change in law or a waiver to existing law, and should seek reductions in federal restrictions to speed 
accessing methadone treatment. Another important step would be to establish 24/7 available crisis walk-in centers for behavioral health that can determine a diagnosis and provide up to 23 hours of on-site (non-24-hour inpatient) care before "warm handoff" discharge to inpatient admission, rehab, or outpatient continuing care. Medication initiation should also be available at these sites.

\section{Focus on High-Risk Populations}

Outreach should be expanded to high-risk populations, such as pregnant and addicted women and newborns, Drug Court participants and postincarceration populations, post-detox/rehab populations, youth (18-25), and returning veterans. Drug take-back boxes should be more extensively deployed. A system that provides $24 / 7$ access to care points across the state should be developed, and a priority should be assigned for targeted prevention and enhanced training for parents, clergy, and others in the community.

\section{Make More Expansive Use of Specialty Courts}

There should be expanded use of Drug Courts and, where appropriate, Family Court, guided by twenty-first-century best practices, including peer support. ${ }^{7}$ Best practices from other parts of the country, such as the LEAD (Seattle) model, should be considered for adoption here, and there should be additional skill resource and skill development for law enforcement.

\section{Provide Adequate Time for Treatment}

There needs to be support for retention in treatment sufficient to achieve medical stabilization and early recovery. Withdrawal management or "detox" alone should only be offering medical stabilization as the precursor to treatment. Beyond treatment, programs should offer recovery as a return to a positive life for oneself and in the community. Individual, family, and community recovery measures should be established to build and measure clinical outcomes and resiliency, i.e., strengthened individual and community recovery capital. For sustained overdose and substance use reduction, implement a statewide Recovery-Oriented System of Care (SAMHSA 2012; White 2008). Ninety-day minimal care should be encouraged and should be a monitored and managed goal.

\section{Collaborate and Implement Community Plans}

Leaders in each community should initiate community meetings that bring together citizens, public health and public safety leaders, and payers to design and implement a local plan that includes initiatives such as addressing stigma 
and overdose while building individual and community resilience and health, i.e., increasing recovery capital. Recovery capital is measurable as the quantity and quality of internal and external resources that the community can bring to bear on the initiation and maintenance of recovery. Having a local plan empowers each community but does not replace broader efforts to address root causes of the problem, e.g., increased and improved medical training and preparedness, increased law enforcement efforts, and aligned new policy development for communities to know, and upon which to act. All final solutions are local. Families and communities are the beginning and end of those solutions.

\section{Collect and Learn from Data}

Each overdose should be anonymously reviewed to strengthen local systems, including the study of failed early-intercept points for system improvement. This data can be used to understand trends and to improve local efforts, while larger efforts support broader and longer-term solutions, i.e., building recovery capital. The thoughtful use of this data will also convey to each family that no death is without meaning and that from each loss, system and community strength will grow: hope arises from loss. The identities of victims are not needed, so HIPPA or other confidentiality concerns need not be barriers.

\section{Augment Professional Efforts}

The building of peer and family supports in each community can augment the existing professional workforce. Local universities or colleges, along with professional counselor organizations, should build career pathways for those in sustained recovery or those with firsthand experience of the illness (e.g., family members) to become "Peer Supports" that can help individuals, treatment agencies, or families and communities in ways that other professionals cannot. For example, peers can be a warm handoff person, support a person to enter treatment, reach out to families who need help, increase retention in treatment, assist with transportation, etc. Pennsylvania now has a certification path for Peer Supports, ${ }^{8}$ and increasingly public health payers are beginning to recognize and pay for these services. The development of these workers, whether paid or volunteer, is proving essential to the long-term realization of success in addressing overdose and ultimately preventing addiction. Peers are not a replacement for professional treatment but are an enhancement of it. In America today, there are over 40 million adults living in recovery (White 2012), and one in four families is personally affected by substance use (NIDA 2016c). 


\section{Strengthen Integrated Care}

The twenty-first-century model for care is integrated care with parity. In recent years, large health systems and medical practices have found that community-based generalist outpatient care (e.g., primary care, community health centers, group practices, etc.) can be more efficient in reaching all populations with quality care (Christensen et al. 2009). What if each such outpatient center had a certified addiction specialist physician or nurse practitioner and behavioral counselor with peer accessibility that then naturally brought this specialized service to the community? These centers would indeed be meeting community needs without having to face so many other issues and barriers, e.g., lack of knowledge, access, losing patients in referrals. In San Francisco, at the Zuckerberg San Francisco General Hospital, all physicians in all specialties are trained to assess and treat addiction in the location where the patient is seen-with addiction-certified specialists on $24 / 7$ call. ${ }^{9}$

In Boston, based on a community needs assessment, Massachusetts General Hospital opened specialized addiction services with 24/7 access to all levels of care, including same-day buprenorphine treatment and referral. To assure no one gets lost in the cracks, each patient is assigned a recovery coach. ${ }^{10}$ Outpatient integration of care is also growing via 23/7 Crisis Stabilization Centers linked to hospitals, and behavioral experts being added to generalist sites such as primary care, health centers, family practice groups, etc.

\section{Recovery-The Path to Hope and Solution}

Informed national and local leaders have all concluded that we can neither legislate nor arrest our way out of this epidemic. We cannot even treat our way out of it without long-term specifically designed universal, selected, and indicated prevention strategies built upon a unified vision and driven by a coordinated and determined implementation effort that recognizes existing barriers and overcomes them. This means doing nearly everything noted in this document at the local level-with leadership from science and policymakers alongside strong citizen involvement. The solution, like the problem, is complex and requires complex adaptive reasoning with culturally sensitive community approaches and systems, such as those used in addressing diabetes, HIV, Zika, and other complex, societal illnesses (Institute of Medicine 2001). Today's established institution-based medical model can't go far enough to meet the present challenges. We must first establish the will and a vision that can lead to recovery and hope-recovery for each person, each family, each community, each county, each state, leading to recovery for our nation. A vision that can do this is required. We cannot afford to cast off a single person without simultaneously losing our way. 
Who we are as a society is the true challenge of addiction and this epidemic. It has been a long time coming (see Burke and Buchanich in this issue). The challenge of addiction and all its societal manifestations needs to be continually addressed for its many root causes. Adapting a solution using complex, adaptive approaches developed by local groups across America and around the world means inserting their voices with best practice and the emerging science and solutions for recovery. This twenty-first-century "medical model" (Barber 2012; Flaherty 2012) promises to each person and family who seeks help an opportunity for recovery, i.e., an improved quality of life, and not just partial care or the maintenance of misery. Communities across America are insisting on the values of wellness and recovery as their standard of care with their limited public dollars and stronger collective approaches to the problem. Recovery, as defined above, is offered to everyone, family and the community at large, by bringing shared goals and measures into a partnership with applied best science and practice.

Recovery can occur with medication or without medication. Recovery has many pathways with specific phases and can be measured in each person and family as increased resilience, strength, and wellness (individual recovery capital); or in each community (community recovery capital) as assets to prevent, treat, and end addiction growth (Flaherty, Kurtz, and White 2014; White and Kurtz 2008, 26). Known as "recovery-oriented systems of care" (ROSC) for mental health and substance use, ROSC is nothing short of transformative as it moves health systems away from institution-based, crisis-oriented, acute, deficit-focused, and professionally directed and controlled models of care to a vision of care that is directed by each community and those people in recovery in the community (Christensen, Grossman, and Hwang 2009; Institute of Medicine 2001; SAMHSA 2012). A recovery-oriented system of care, when applied, is a grassroots-originated, complex, adaptive systems approach. It is a network of indigenous and professional services and relationships that builds the health of each community from within with prevention, early intervention, and treatment linked to short-term, long-term, and sustained recovery of individuals, families, and the community. Further, ROSC builds the local values and policies into a culture and environment that will remain continuously supportive of these recovery practices in general medical (e.g., integrated and primary care) and specialty care (e.g., acute substance use treatment).

A ROSC system joins the community with providers and leaders to adopt and implement principles and objectives used in implementation, e.g., in a county (Hancock, Ohio), a city (Philadelphia), or in states such as Connecticut, Texas, North Carolina, Ohio, etc. (Kelly and White 2011). ROSC measures are now embedded in the federal funding to each state for implementation within that state's block grant. A ROSC system is not a federal, state, or local 
agency, but a community network of indigenous and professional services and relationships that can achieve and support the long-term recovery of individuals and families within the larger cultural and policy environment of each community in which overdose is to be ended through specifically designed prevention, early-intervention, treatment, and long-term recovery (SAMHSA 2010). By combining the strategies of overdose prevention (including harm reduction) with best science and practice within a ROSC, short- and long-term solutions to this epidemic become accessible and hope returns as a reality.

Resources and a full bibliography of this modern science, including evaluations of it, are available at www.samhsa.gov (search: recovery); williamwhitepapers.com; the Recovery Institute at Harvard University (info@recoveryanswers.org); the SAMHSA-funded Addiction Technology Transfer Centers (www.attcnetwork.org); or the Institute for Research, Education and Training in the Addictions (IRETA) in Pittsburgh, PA (www.ireta .org). ROSC, in part or in whole, is now emerging across the globe and in over 30 states. ROSC, with the system changes noted in this document, brings state, county, and community leadership, guidance, and implementation for long-term resolution of the epidemic, stigma, and illness. It is hope made real through an empowered community. Our policymakers need to understand that, while there are no quick solutions to the problem of addiction and overdose, a community-based solution joined with science, best practice, and local systems of care offers to Pennsylvania-and the country-the best option for a long-term solution to today's opioid challenge. It addresses the barriers and challenges while offering a sustainable twenty-first-century model of care for each person that can end an epidemic through the recovery from its causes. 


\section{APPENDIX A}

\begin{tabular}{|c|c|c|c|c|}
\hline \multicolumn{5}{|c|}{ The Continuum of Care to Address Addiction (Surgeon General 2016) } \\
\hline $\begin{array}{l}\text { Enhancing } \\
\text { Health }\end{array}$ & $\begin{array}{l}\text { Primary } \\
\text { Prevention }\end{array}$ & $\begin{array}{l}\text { Early } \\
\text { Intervention }\end{array}$ & Treatment & Recovery Support \\
\hline $\begin{array}{l}\text { Promoting } \\
\text { optimum physical } \\
\text { and mental } \\
\text { health and well- } \\
\text { being, free from } \\
\text { substance misuse, } \\
\text { through health } \\
\text { communication } \\
\text { and access to } \\
\text { health care } \\
\text { services, income } \\
\text { and economic } \\
\text { security, and } \\
\text { workplace } \\
\text { certainty. }\end{array}$ & $\begin{array}{l}\text { Addressing } \\
\text { individual and } \\
\text { environmental } \\
\text { risk factors } \\
\text { for substance } \\
\text { use through } \\
\text { evidence-based } \\
\text { programs, } \\
\text { policies, and } \\
\text { strategies. }\end{array}$ & $\begin{array}{l}\text { Screening } \\
\text { and detecting } \\
\text { substance use } \\
\text { problems at an } \\
\text { early stage and } \\
\text { providing brief } \\
\text { intervention, as } \\
\text { needed. }\end{array}$ & $\begin{array}{l}\text { Intervening through } \\
\text { medication, } \\
\text { counseling, and other } \\
\text { supportive services to } \\
\text { eliminate symptoms } \\
\text { and achieve and } \\
\text { maintain sobriety, } \\
\text { physical, spiritual, } \\
\text { and mental health, } \\
\text { and maximum } \\
\text { functional ability. } \\
\text { Levels of care } \\
\text { include: Outpatient } \\
\text { Services; Intensive } \\
\text { Outpatient/Partial } \\
\text { Hospitalization } \\
\text { Services; Residential/ } \\
\text { Inpatient Services; } \\
\text { and Medically- } \\
\text { Managed Intensive } \\
\text { Inpatient Services. }\end{array}$ & $\begin{array}{l}\text { Removing barriers } \\
\text { and providing } \\
\text { supports to aid the } \\
\text { long-term recovery } \\
\text { process. Includes } \\
\text { a range of social, } \\
\text { educational, legal, } \\
\text { and other services } \\
\text { that facilitate } \\
\text { recovery, wellness, } \\
\text { and improved } \\
\text { quality of life. }\end{array}$ \\
\hline
\end{tabular}

\section{APPENDIX B: SUMMARY OF NATIONAL, PENNSYLVANIA, AND OTHER OVERDOSE PREVENTION PLANS AND ACTIONS}

This summary is not meant to be exhaustive of all efforts but does reflect links to recent key federal, Pennsylvania, and others states' resources and efforts to address overdose.

\section{National Resources to Address Overdose}

Key national guiding documents and resources can be found in the U.S. Department of Health and Human Services (www.hhs.gov), the National Center For Disease Control (www.cdc.gov), the Substance Abuse and Mental Health Services Administration (www.samhsa.gov), the National Institute for Drug Abuse (www.drugabuse.gov), the Health Resources and Services Administration (www.hrsa.gov), the White House Office of National Drug Control and Policy (www.ondcp.gov), the American Society for Addiction Medicine (www.asam.org), the American Psychiatric Association (www.psychiatry .org), and within health care-focused foundations such as the Pew Charitable Trusts (www.pewtrusts.org), or insurance plans and managed care companies 
such as Community Care Behavioral Health in Pennsylvania (www.ccbh.org) or nationally, Optum Health (www.optum.com). Once at the site, search "opioids" or "overdose."

Many of these entities have their recommendations combined in the November 2016 Surgeon General's Report: Facing Addiction in America (see: addiction.surgeongeneral.gov/). In July 2017, the newly commissioned White House Task Force submitted its "interim plan" calling for a declaration of a National State of Emergency, to increase beds and promote barrier regulation removal, among other things. This full "interim" report is available at: www.whitehouse.gov/sites/whitehouse.gov/files/ondcp/commissioninterim -report.pdf.

\section{Pennsylvania Resources to Address Overdose}

Pennsylvania itself has produced several notable plans replete with recommendations. Pennsylvania and the University of Pittsburgh School of Pharmacy have long collaborated to offer a Technical Assistance Center that provides a wealth of information on the status of overdose death rates and causes across Pennsylvania through an interactive website at www.peru.pitt .edu/pennsylvania-heroin-overdose-prevention-technical-assistance-center/. This database is updated daily, providing up-to-date information about overdose prevention, data on overdose deaths from Pennsylvania counties, and data on a variety of factors that can support county prevention efforts. In 2016 the University of Pittsburgh's Institute of Politics published a comprehensive plan entitled A Continuum of Care Approach: Western Pennsylvania's Response to the Opioid Epidemic, available at iop.pitt.edu/ publications/policy-and-research-reports (see under "Health \& Human Services"). This report expanded on the 32 recommendations presented in the (Western Pennsylvania) U.S. Attorney's Working Group on Drug Overdose and Addiction: Prevention, Intervention, Treatment and Recovery Final Report and Recommendations, published in September 2014, available at: www.justice.gov/sites/default/files/usao-wdpa/legacy/2014/09/29/ US\%20Attorney\%27s\%20Working $\% 20$ Group $\% 20$ on $\% 20$ Addiction $\% 20$ Final\%20Report.pdf. The Pennsylvania Department of Drug and Alcohol Programs has a published response at www.ddap.pa.gov/overdose/Pages/ Department\%20Focus\%20on\%20Addressing\%20Overdose.aspx, and a 2016-2017 State Plan that includes many OD prevention and treatment initiatives. This plan is available at www.ddap.pa.gov/Reports/State\%20Plan\%20 and\%20Annual\%20Reports/2016-2017\%20DDAP\%20State\%20Plan.pdf. 
The PA Association of County Drug and Alcohol Administrators has a Plan (opioidaction.org/report/), as does the Center for Rural Pennsylvania (www.rural.palegislature.us/publications_heroin_and_opioid_addiction _public_hearings.html).

\section{Other Plans to Address Overdose}

Other states have also published plans, as have successful programs such as Vermont's "Hub/Spoke" model (dvha.vermont.gov/administration/1hub -spoke-health-home-framework-payment-12-10-12.pdf), which is being replicated in part via Centers of Excellence in Pennsylvania with state and federal funds (21st Century Cures Act). See: dhs.pa.gov/citizens/ substanceabuseservices/centersofexcellence/index.html.

\section{NOTES}

1. A chemical substance that binds to and activates certain receptors on cells, causing a biological response. Fentanyl and methadone are examples of opioid receptor agonists. Suboxone is a partial agonist. Agonists are addictive.

2. See the video here: https://youtu.be/x2SP0GusLp0.

3. An overview can be found at: https://ncsacw.samhsa.gov/resources/opioid-use -disorders-and-medication-assisted-treatment/treatment-of-opioid-use-disorders-in -pregnancy.aspx.

4. See www.myaddiction.com/articles/drugs/what-is-the-addiction-severity-index.

5. http://www.who.int/substance_abuse/activities/treatment_opioid_dependence/ en/.

6. See: https://www.cdc.gov/drugoverdose/pdf/Guidelines_Factsheet-a.pdf .

7. See: www.NDCI.org.

8. See: info@pacertboard.org.

9. For more information, contact D. Coffa, M.D, at DianaCoffa@ucsf.edu.

10. The point of contact for more information is Sarah Wakeman, M.D., FASAM, at swakeman@partners.org.

\section{REFERENCES}

Alderks, C. E. 2017. Trends in the Use of Methadone, Buprenorphine, and Extended-release Naltrexone at Substance Abuse Treatment Facilities: 2003-2015 (Update). Rockville, MD: Substance Abuse and Mental Health Services Administration.

American Academy of Pain Management (AAPM). 2015. Pain Management Guidelines. Available at http://www.painmed.org/library/clinical-guidelines/. Accessed August 15, 2017.

American Medical Association (AMA). 1998. "Effective Medical Treatment of Opiate Addiction. National Consensus Development Panel on Effective Medical Treatment of Opiate Addiction." The Journal of the American Medical Association 280 (December): 1936-1943. 
2018. Reversing the Opioid Epidemic. Available at https://www.end-opioid -epidemic.org/. Accessed April 20, 2018.

American Society on Addiction Medicine (ASAM). 2017. "Definition of Addiction." Available at https://www.asam.org/quality-practice/definition-of-addiction. Accessed August 15, 2017.

Banta-Green, C. J., J. O. Merrill, S. R. Doyle, D. M. Boudreau, and D. A. Calsyn. 2009. "Opioid Use Behaviors, Mental Health and Pain-Development of a Typology of Chronic Pain Patients.” Drug \& Alcohol Dependency 104 (September): 34-42.

Barber, M. 2012. "Recovery as the New Medical Model for Psychiatry.” Psychiatric Services 63 (March): 277-279.

Campbell, J. N. 1996. “APS 1995 Presidential Address.” Pain Forum 5 (Spring): 85-88.

Centers for Disease Control and Prevention (CDC). 2017a. "Opioid Overdose Prescribing Data." August 30. Available at https://www.cdc.gov/drugoverdose/data/prescribing. html. Accessed April 20, 2018.

_. 2017b. "What States Need to Know about PDMPs." October 3. Available at https:// www.cdc.gov/drugoverdose/pdmp/states.html. Accessed December 29, 2017.

Christensen, C. M., J. H. Grossman, and J. Hwang. 2009. The Innovator's Prescription: A Disruptive Solution for Health Care. New York: McGraw Hill.

Collins, S. E., H. S. Lonczak, and S. L. Clifase. 2015. LEAD Program Evaluation: Criminal Justice and Legal System Utilization and Associated Costs. Seattle: University of Washington, Harborview Medical Center, Harm Reduction Research and Treatment Lab.

Commonwealth of Pennsylvania Department of Drug and Alcohol Programs. 2014. Pennsylvania's Placement Criteria for Adults, 3rd ed. Harrisburg: Pennsylvania Department of Drug and Alcohol Programs. Available at http://www.ddap.pa.gov/Manuals/ PA\%20Client\%20Placement\%20Criteria\%20(PCPC)\%20Edition\%203\%20Manual .pdf. Accessed August 17, 2017.

DeFlavio, J. R., S. A. Rolin, B. R. Nordstrom, and L. A. Kazal, Jr. 2015. "Analysis of Barriers to Adoption of Buprenorphine Maintenance Therapy by Family Physicians." Rural Remote Health 15 (February): 1-11.

D’Onofrio, G., P. G. O’Connor, and M. V. Pantalon. 2015. “Emergency DepartmentInitiated Buprenorphine/Naloxone Treatment for Opioid Dependence: A Randomized Clinical Trial." The Journal of the American Medical Association 31 (April): 1636-1644.

Fishbain, D.A., B. Cole, J. Lewis, H. L. Rosomoff, and R. S. Rosomoff. 2008. "What Percentage of Chronic Nonmalignant Pain Patients Exposed to Chronic Opioid Analgesic Therapy Develop Abuse/Addiction and/or Aberrant Drug-Related Behaviors? A Structured Evidence-Based Review." Pain Med 9 (May-June): 444-459.

Flaherty, M., ed. 2006. Special Report: A Unified Vision for the Prevention and Management of Substance Abuse Disorders; Building Resiliency, Wellness and Recovery-A Shift from an Acute Care to a Sustained Care Recovery Management Model. Pittsburgh: Institute for Research, Education and Training in the Addictions.

—. 2012. "A Medical Model for Today." Psychiatric Services 63 (May): 510.

Flaherty, M., E. Kurtz, and W. White. 2014. "An Interpretive Phenomenological Analysis of Secular, Spiritual and Religious Pathways of Long-Term Recovery." Alcoholism Treatment Quarterly 32 (October): 337-356.

Foote, J., C. Wilkens, N. Kosanke, and S. Higgs. 2014. Beyond Addiction. How Science and Kindness Help People Change (CRAFT). New York: Simon and Schuster.

Granfield, R., and W. Cloud. 1999. Coming Clean: Overcoming Addiction without Treatment. New York: New York University Press. 
Hickton, D. J., and M. L. Leary. 2015. National Heroin Task Force Final Report and Recommendations. Washington, DC: U.S. Department of Justice and White House Office of National Drug Control Policy.

Hoge, M. A., G. E. Stuart, J. A. Morris, Y. H. Huey, M. T. Flaherty, and M. Paris. 2017. "Behavioral Health Workforce Development in the United States." In Workforce Development Theory and Practice in the Mental Health Sector, eds. M. Smith and A. Jury. Hershey, PA: IGI Global, 37-59.

Hoge, M., G. Stuart, J. Morris, M. T. Flaherty, M. Paris, and E. Goplerud. 2013. "Mental Health and Addiction Workforce Development: Federal Leadership Is Needed to Address the Growing Crisis." Health Affairs 32 (November): 2005-12.

Huhn, A. S., and K. E. Dunn. 2017. "Why Aren't Physicians Prescribing More Buprenorphine?" Journal of Substance Abuse Treatment 78 (July): 1-7.

Hyde, P. S. 2013. Report to Congress on the Nation's Substance Abuse and Mental Health Workforce Issues. Washington, DC: U.S. Department of Health and Human Sciences, Substance Abuse and Mental Health Services Administration (SAMHSA). Available at https://store.samhsa.gov/shin/content//PEP13-RTC-BHWORK/PEP13-RTC -BHWORK.pdf. Accessed on August 17, 2017.

Institute of Medicine. 2001. Crossing the Quality Chasm. The New Health System for the 21st Century. Washington, DC: National Academy Press, Appendix B, 309-322.

Jones, C. M. 2013. "Heroin Use and Heroin Use Risk Behaviors among Nonmedical Users of Prescription Opioid Pain Relievers-United States, 2002-2004 and 2008-2010.” Drug and Alcohol Dependence 132 (September): 95-100.

Joseph, H., S. Stancliff, and L. Langrod. 2000. "Methadone Maintenance Treatment (MMT): A Review of Historical and Clinical Issues.” Mount Sinai Journal of Medicine 67 (October-November): 347-364.

Kakko, J., K. D. Svanborg, M. J. Kreek, and M. Heilig. 2003. “1-Year Retention and Social Function after Buprenorphine-Assisted Relapse Prevention Treatment for Heroin Dependence in Sweden: A Randomized, Placebo-Controlled Trial." Lancet 361 (February): $662-668$.

Kelly, J., and W. White. 2011. Addiction Recovery Management: Theory, Research and Practice. New York: Humana Press.

Kelly, J. F., S. J. Dow, and C. Westerhoff. 2010. "Does Our Choice of Substance-Related Terms Influence Perceptions of Treatment Need? An Empirical Investigation with Two Commonly Used Terms." Journal of Drug Issues 40 (October): 805-818.

Kolodny, A., D. T. Courtwright, C. S. Hwang, P. Kreiner, J. L. Eadie, T. W. Clark, and G. C. Alexander. 2015. "The Prescription Opioid and Heroin Crisis: A Public Health Approach to an Epidemic of Addiction." Annual Review of Public Health 36 (March): 559-574.

Lord, R. 2018. "Doctors Are Prescribing Fewer Opioids Following Measures by State Insurers." Pittsburgh Post-Gazette, January 8.

McLellan, A. T., D. C. Lewis, C. P. O’Brien, and H. D. Kleber. 2000. “Drug Dependence, a Chronic Medical Illness: Implications for Treatment, Insurance, and Outcome Evaluation." The Journal of the American Medical Association 284 (October): 16891695.

McLellan, A. T., L. Luborsky, C. P. O’Brien, and G. E. Woody. 1980. “An Improved Diagnostic Instrument for Substance Abuse Patients: The Addiction Severity Index." Journal of Nervous and Mental Diseases 168: 26-33.

Mee-Lee, D., G. D. Shulman, M. J. Fishman, D. R. Gastfriend, and M. M. Miller, eds. 2013. The ASAM Criteria: Treatment Criteria for Addictive, Substance-Related, and 
Co-Occurring Conditions, 3rd ed. Chevy Chase, MD: American Society of Addiction Medicine.

Mezei, L., and B. Murison. 2011. "Pain Education in North American Medical Schools." Journal of Pain 12 (December): 1199-1208.

Morley-Forster, P. K., J. V. Pergolizzi, R. Taylor, R. A. Axford-Gatley, and E. M. Sellers. 2013. "Mitigating the Risk of Opioid Abuse through a Balanced Undergraduate Pain Medicine Curriculum." Journal of Pain Research 6 (December): 791-801.

Muhuri, P. K., J. C. Groener, and M. C. Davies. 2013. Associations of Nonmedical Pain Reliever Use and Initiation of Heroin Use in the United States. Rockville, MD: Substance Abuse and Mental Health Services Administration. Available at http://archive .samhsa.gov/data/2k13/DataReview/DR006/nonmedical-pain-reliever-use-2013.pdf. Accessed August 15, 2017.

National Institute on Drug Abuse (NIDA). 2016a. "Drug Facts: Genetics and Epigenetics of Drug Addiction.” February. Available at https://www.drugabuse.gov/sites/default/ files/genetics_and_epigenetics_drugfacts_2.pdf. Accessed February 1, 2018.

_ 2016b. "Principles of Substance Abuse Prevention for Early Childhood." March. Available at https://www.drugabuse.gov/publications/principles-substance-abuse -prevention-early-childhood. Accessed February 1, 2018.

_. 2016c. "Rates of Nonmedical Prescription Opioid Use and Opioid Use Disorder Double in 10 Years." June 22. Available at https://www.niaaa.nih.gov/news-events/ news-releases/rates-nonmedical-prescription-opioid-use-and-opioid-use-disorder -double-10. Accessed February 1, 2018.

. 2016d. "Buprenorphine Prescribers Treat below Current Patient Limits." September 20. Available at https://www.drugabuse.gov/news-events/news-releases/2016/09/ buprenorphine-prescribers-treat-below-current-patient-limits. Accessed February 1, 2018.

—.2016e. "Media Guide." October. Available at https://www.drugabuse.gov/publications/ media-guide/science-drug-abuse-addiction-basics. Accessed February 1, 2018.

_. 2018a. "Drug Facts.” January. Available at https://www.drugabuse.gov/publications/ drugfacts/heroin. Accessed February 1, 2018.

- 2018b. Principles of Drug Abuse Treatment: A Research Based Guide, 3rd ed. Available at https://www.drugabuse.gov/publications/principles-drug-addiction -treatment-research-based-guide-third-edition/acknowledgments. Accessed February $1,2018$.

—.2018c. "Magnitude_Drug Abuse Is Costly." Available at https://archives.drugabuse .gov/publications/drug-abuse-addiction-one-americas-most-challenging-public -health-problems/magnitude. Accessed February 1, 2018.

Office of National Drug Control Policy (ONDCP). 2013. National Drug Control Strategy. Washington, DC: White House. Available at http://www.whitehouse.gov/ondcp/2013national-drug-strategy. Accessed June 19, 2017.

Pittsburgh Post-Gazette Editorial Board. 2017. "Dying Young: The Opioid Crisis is Affecting U.S. Life Expectancy.” Pittsburgh Post-Gazette, December 27.

Porter, J., and H. Jick. 1980. "Addiction Rare in Patients Treated with Narcotics.” New England Journal of Medicine 302 (January): 123.

Quinones, S. 2015. Dreamland: The True Tale of America's Opiate Epidemic. New York: Bloomsbury Press.

Robert Wood Johnson Foundation. 2001. Substance Abuse: The Nation's Number One Health Problem. Princeton, NJ: Brandeis University Schneider Institute for Health Policy. 
Rudd, R. A., P. Seth, F. David, and L. Scholl. 2016. "Increases in Drug and Opioid-Involved Overdose Deaths-United States, 2010-2015." Morbidity and Mortality Weekly Report 65 (December): 1445-1452.

Sauter, M. B. 2016. "10 States with the Most Drug Overdoses.” 24/7 Wall Street Journal, June 24. Available at http://247wallst.com/special-report/2016/06/24/10-states-with -the-most-drug-overdoses/2/. Accessed August 14, 2017.

Scott, C. K., and M. L. Dennis. 2007. "Managing Addiction as a Chronic Condition." Addiction Science and Clinical Practice 4 (December): 45-55.

Sliboda, Z., M. Glantz, and R. Tarter R. 2012. "Revisiting the Concepts of Risk and Protective Factors for Understanding the Etiology and Development of Substance Use and Substance Use Disorders: Implications for Prevention." Substance Use \& Misuse 47 (June-July): 944-962.

Stein, B. D., A. J. Gordon, A. W. Dick, R. M. Burns, A. Liccardo, R. Pacula, C. M. Farmer, D. L. Leslie, and M. Sorbero. 2015. "Supply of Buprenorphine Waivered Physicians: The Influence of State Policies." Journal of Substance Abuse Treatment 48 (January): $104-111$.

Substance Abuse and Mental Health Services Administration (SAMHSA). 2010. RecoveryOriented Systems of Care (ROSC) Resource Guide. September. Available at https:// www.samhsa.gov/sites/default/files/partnersforrecovery/docs/ROSC_Resource_ Guide_Book.pdf. Accessed February 1, 2018.

- 2012. Addictions and Mental Health Recovery Dialogue: Similarities and Differences in Our Communities. September 13. Available at https://www.samhsa.gov/sites/ default/files/similarities-differences-dialogue.pdf. Accessed February 1, 2018.

_ 2013. "Report to Congress on the Nation's Substance Abuse and Mental Health Workforce Issues.” January 24. Available at https://store.samhsa.gov/shin/content/ PEP13-RTC-BHWORK/PEP13-RTC-BHWORK.pdf. Accessed February 1, 2018.

- 2016. "Medication-Assisted Treatment of Opioid Use Disorders." Available at https://store.samhsa.gov/product/Medication-Assisted-Treatment-for-Opioid -Addiction-in-Opioid-Treatment-Programs/SMA12-4108. Accessed February 1, 2018.

Sutherland, G., G. Andrews, C. Taylor, G. Phillips, M. Gossop, and R. Brady. 1986. "The Measurement of Opiate Dependence." Addiction 81 (April): 485-494.

Tarter, R. E., G. Cochran, and M. Reynolds. 2018. "Prevention of Opioid Addiction." Commonwealth: A Journal of Pennsylvania Politics and Policy 20 (2-3): 37-58.

U.S. Department of Health and Human Services (HHS), Office of the Surgeon General. 2016. Facing Addiction in America: The Surgeon General Report on Alcohol, Drugs, and Health. Washington, DC: Substance Abuse and Mental Health Services Administration.

U.S. Department of Health and Human Services (HHS), Behavioral Health Coordinating Committee, Prescription Drug Abuse Subcommittee. 2013. "Addressing Prescription Drug Abuse in the United States, Current Activities and Future Opportunities." Washington, DC: U.S. Department of Health and Human Services. Available at http// www.cdc.gov/drugoverdose/pdf/hhs_prescription_drug_abuse_report_09.2013.pdf. Accessed February 1, 2018

U.S. Department of Justice (DOJ). 2001. Substance Abuse-The Nation's Number One Health Problem. May. Washington, DC: U.S. Department of Justice. Available at https://www.ncjrs.gov/pdffiles1/ojjdp/fs200117.pdf. Accessed February 1, 2018.

U.S. Drug Enforcement Agency and University of Pittsburgh School of Pharmacy. 2017. Analysis of Overdose Deaths in Pennsylvania, 2016. Philadelphia: DEA Philadelphia 
Division and the University of Pittsburgh. Available at https://info.publicintelligence .net/DEA-OverdoseDeathsPA-2016.pdf. Accessed February 1, 2018.

U.S. Government Accountability Office (GAO). 2003. OxyContin Abuse and Diversion and Efforts to Address the Problem. Washington, DC: United States Government Accounting Office.

Vance, J. D. 2016. Hillbilly Elegy: A Memoir of a Family and Culture in Crisis. New York: Harper Collins.

Volkow, N. 2014. Testimony to the Senate Caucus on International Narcotics Control. "America's Addiction to Opioids: Heroin and Prescription Drug Abuse." May 14. Available at https://www.drugabuse.gov/about-nida/legislative-activities/testimony -to-congress/2016/americas-addiction-to-opioids-heroin-prescription-drug-abuse. Accessed February 1, 2018.

— 2017. Testimony to Congress. "Federal Efforts to Combat the Opioid Crisis: A Status Update on CARA and Other Initiatives." October 25. Available at https://www .drugabuse.gov/about-nida/legislative-activities/testimony-to-congress/2017/federal -efforts-to-combat-opioid-crisis-status-update-cara-other-initiatives. Accessed February $1,2018$.

Wakeman, S. E., and J. D. Rich. 2015. "Addiction Treatment within the U.S. Correctional Facilities: Bridging the Gap between Current Practice and Evidenced-Based Care." Journal of Addictive Diseases 34 (June): 220-225.

Wesson, D. R., and W. Ling. 2003. "The Clinical Opiate Withdrawal Scale (COWS)." Journal of Psychoactive Drugs 35 (2): 253-259.

White, W. L. 2008. Recovery Management and Recovery-Oriented Systems of Care: Scientific Rationale and Promising Practices. Pittsburgh, PA: Northeast ATTC, Great Lakes ATTC and Philadelphia Department of Behavioral Health and Disability.

- 2012. Recovery/Remission from Substance Use Disorders: An Analysis of Reported Outcomes in 415 Scientific Reports, 1868-2011. Pittsburgh: Philadelphia Department of Behavioral Health and Intellectual disAbility Services, Great Lakes Addiction Technology Transfer Center. Available at https://www.naadac.org/assets/1959/ whitewl2012_recoveryremission_from_substance_abuse_disorders.pdf. Accessed February 1, 2018.

White, W., and E. Kurtz. 2008. Recovery-Linking Addiction Treatment \& Communities of Recovery: A Primer for Addiction Counselors and Recovery Coaches. Pittsburgh: Northeast ATTC. Available at http://www.williamwhitepapers.com/ pr/2006RecoveryLinkageMonograph.pdf. Accessed February 1, 2018.

White, W., and L. Mojer-Torres. 2010. Recovery-Oriented Methadone Maintenance. Pittsburgh: Northeast ATTC, Great Lakes ATTC and Philadelphia Department of Behavioral Health and Mental Retardation Services. Available at http://www.william whitepapers.com. Accessed February 1, 2018.

Michael T. Flaherty is a clinical psychologist specializing in addiction treatment and recovery. He has over 37 years of practice and leadership of major institutions including the St. Francis Institute for Psychiatry and Addiction Services and the Institute for Research, Education and Treatment of Addiction in Pittsburgh, Pennsylvania. He has authored many articles and studies on addictions, workforce development, and recovery. Recently he served as a senior adviser for the U.S. Department of Justice/White House Office of National Drug Control Policy Heroin Task Force, and as coleader of the U.S. Attorney Western Pennsylvania Task Force on Overdose Prevention. 